\title{
Regional thickness of the compacted and trabeculated layers of the left ventricle in young patients presenting with ventricular dysrhythmias, a Cardiac MRI study
}

\author{
Moneal Shah ${ }^{*}$, Lynette Duncanson ${ }^{2}$, Ellen Cummings ${ }^{2}$, Nathaniel Reichek², Jie J Cao ${ }^{2}$ \\ From 15th Annual SCMR Scientific Sessions \\ Orlando, FL, USA. 2-5 February 2012
}

\section{Summary}

We sought to characterize the compacted and trabeculated layers of the left ventricle in patients presenting with ventricular dysrhythmias. Our results showed the dysrhythmic group had a statistically significant increase in the trabecular thickness as well as increased prevalence of trabecular to compacted thickness ratio.

\section{Background}

Cardiac MRI (CMR) is increasingly being used clinically to assess patients with ventricular dysrhythmias. Structural heart disease such as non-compaction is associated with dysrhythmic risk. Recent literature has characterized the regional thickness of the compacted and trabeculated layers of the left ventricle (LV) in normal subjects but not in patients with ventricular dysrhythmias. We sought to characterize the regional thickness of the compacted and trabeculated layers in a young community-based ventricular dysrhythmia population.

\section{Methods}

The study consisted of 98 patients under the age of 50 who had undergone CMR for ventricular dysrhythmia evaluation. These patients were compared to 26 agematched normal subjects. Patients who had known cardiomyopathy or myocardial infarction and those referred for AICD evaluation were excluded. SSFP cine images were used to assess cardiac structure and function. Intravenous gadolinium was given for late gadolinium enhancement (LGE) assessment. Regional thickness of

${ }^{1}$ Allegheny General Hospital, Pittsburgh, PA, USA

Full list of author information is available at the end of the article the compacted and trabeculated layers were assessed in short axis cine views in 16 of the standard 17 segments at end-diastole. The trabeculated layer thickness and the ratio of trabeculated to compacted layer were compared between the dysrhythmic and control group.

\section{Results}

The mean age was 37 years and 56 (57\%) were women. In the dysrhythmic group, 45 had premature ventricular contractions (PVC) and 55 had ventricular tachycardia (VT). Mean LV ejection fraction was $54 \pm 7 \%$ in the dysrhythmia group. LGE was present in 10 cases (10\%) but none showed an infarct pattern. On average, the trabeculated layer was significantly larger in the dysrhythmic group than in control group: $3.7 \pm 1.4 \mathrm{~mm}$ vs. $3.0 \pm 1.0$ $\mathrm{mm}$ at base $(\mathrm{p}<0.001), 4.6 \pm 1.3 \mathrm{~mm}$ vs. $3.4 \pm 1.0 \mathrm{~mm}$ in mid segment $(\mathrm{p}<0.001)$ and $5.4 \pm 1.5 \mathrm{~mm}$ vs. $3.5 \pm 0.9 \mathrm{~mm}$ in apical segment $(\mathrm{p}<0.001)$. The prevalence of trabeculated to compacted ratio $\geq 2.0$ was $19 \%$ in controls, $20 \%$ in PVC group and $20 \%$ in VT group $(\mathrm{p}=\mathrm{NS})$. In contrast, the prevalence of a ratio $\geq 2.3$ was 0 in controls, $16 \%$ in PVC group and $11 \%$ in VT group $(\mathrm{p}=0.01)$. The most common areas where the ratio exceeded 2.3 were mid-anterior, mid-anterolateral, apical anterior and apical lateral walls.

\section{Conclusions}

In this young cohort with ventricular dysrhythmias, the trabeculated layer was significantly thicker than agematched controls. Moreover, a trabeculated to compacted ratio greater than 2.3 was only present in patients with ventricular dysrhythmias, but not in normal controls. Our findings suggest that increased 
thickness of the trabeculated layer in young subjects may be associated with the risk of ventricular dysrhythmia.

\section{Funding}

None.

\section{Author details}

'Allegheny General Hospital, Pittsburgh, PA, USA. ${ }^{2}$ St. Francis Hospital, Roslyn, NY, USA

Published: 1 February 2012

doi:10.1186/1532-429X-14-S1-0106

Cite this article as: Shah et al:: Regional thickness of the compacted and trabeculated layers of the left ventricle in young patients presenting with ventricular dysrhythmias, a Cardiac MRI study. Journal of Cardiovascular Magnetic Resonance 2012 14(Suppl 1):0106.

Submit your next manuscript to BioMed Central and take full advantage of:

- Convenient online submission

- Thorough peer review

- No space constraints or color figure charges

- Immediate publication on acceptance

- Inclusion in PubMed, CAS, Scopus and Google Scholar

- Research which is freely available for redistribution

Submit your manuscript at www.biomedcentral.com/submit 